\title{
Determination of spectral decay parameter and Quality factor in Kermanshah region, NW Iran
}

\author{
Mehdi Nouri DELOUEI ${ }^{1}$ (D), Mohammad-Reza GHEITANCHI ${ }^{2, *}$ (D) \\ ${ }^{1}$ Department of Geophysics, Islamic Azad University, Tehran North Branch, Tehran, Iran; \\ e-mail: mndmha@gmail.com \\ ${ }^{2}$ Institute of Geophysics, University of Tehran, Tehran, Iran; \\ e-mail: mrghchee@ut.ac.ir
}

\begin{abstract}
Among important parameters in simulation of earthquake data in high frequencies are the high frequency spectral amplitude decay and the Quality factor. Amplitude spectral decay is determined by the Kappa parameter $(K)$ and the Quality factor $(Q)$ which is usually expressed by a power relation of frequency $(f)$ as $Q=Q_{0} f^{n}$, where $Q_{0}$ is $Q$ at $1 \mathrm{~Hz}$. The 2017 Sarpol-e-Zahab earthquake with magnitude $\mathrm{Mw}=7.3$ in Kermanshah province near the Iran-Iraq border caused extensive destruction and heavy human loss. Thus, the study of different aspects of this event is of high importance. In this paper an attempt is made to partly explain the attenuation properties of this region in Zagros suture zone by determining the Kappa and the Quality factors in this region. In this study, accelerograph records of aftershocks of the above-mentioned earthquake have been analysed. The best linear fit for the Kappa, based on the distance $(R)$ in $\mathrm{km}$, is estimated as: $K=0.0005 R+0.034$ for the horizontal component, which exhibits increase with increasing epicentral distance. The correlation of the Quality factor was also found as $Q=88.6 f^{0.8}$, which is in accordance with an active tectonic region.
\end{abstract}

Key words: Sarpol-e-Zahab earthquake, Kappa factor, Quality factor, spectral decay, Zagros suture zone

\section{Introduction}

The Zagros suture zone is a seismically active region in the Iranian plateau. The seismicity map of Iran from 2000 to 2020 is presented in Fig. 1. More than 50 percent of earthquakes reported by the national seismic network have occurred in Zagros (Mirzaei et al., 1998). This Zagros region is of high importance in terms of seismic risk, since it is a vast and populated region and in recent years earthquakes with high intensities have frequently

\footnotetext{
*corresponding author: e-mail: mrghchee@ut.ac.ir
} 


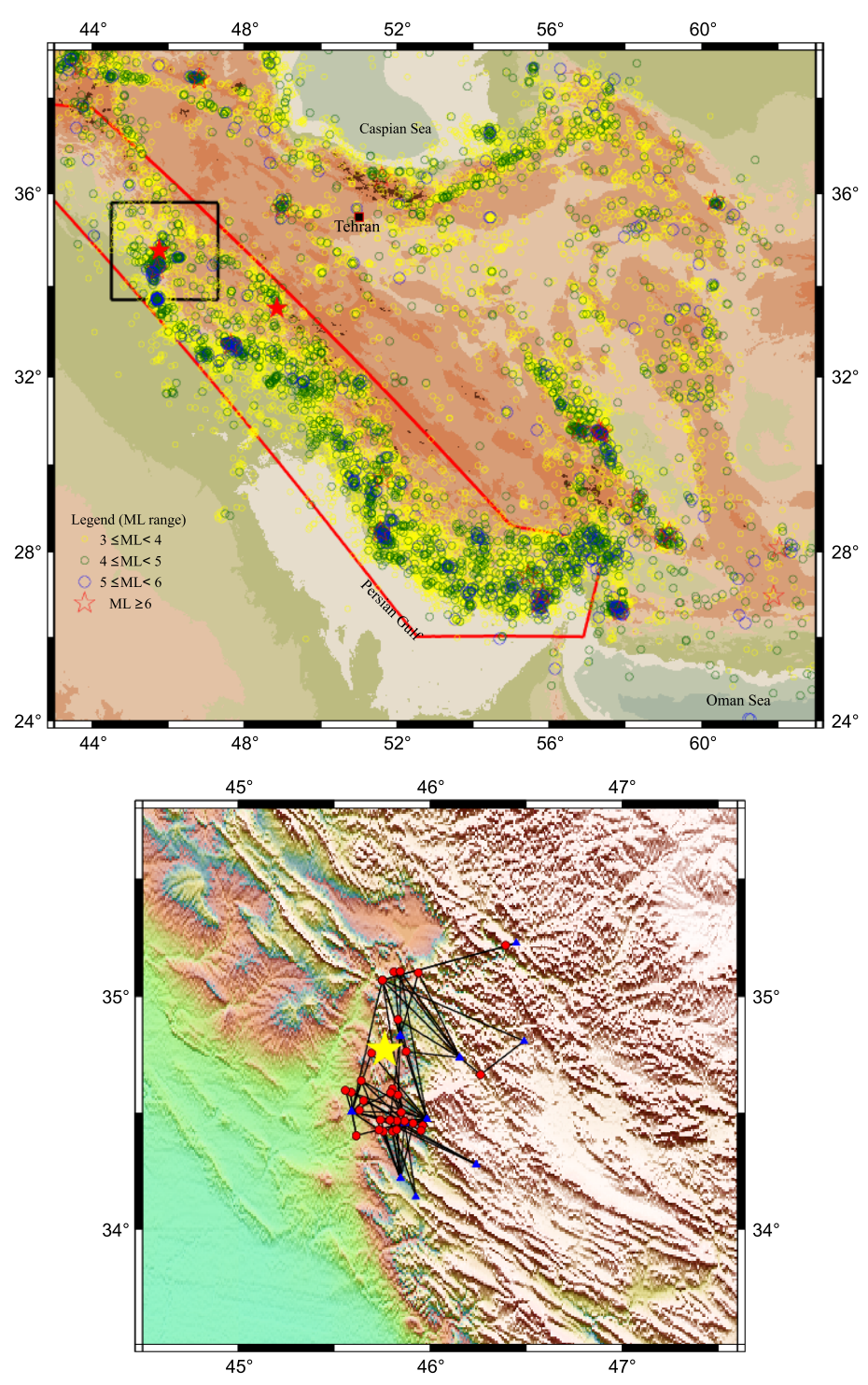

Fig. 1. Seismicity map of Iran from 2000 to 2020 (top). The Zagros region (red line), the study area, which includes Sarpol-e-Zahab and its surroundings (black line) and location of 2017, Sarpol-e-Zahab, $\mathrm{Mw}=7.3$ and 2006, $\mathrm{Mw}=6.1$, Darb-e-Astane earthquake (red star) are also represented. Map of the study area (bottom). Epicentres of aftershocks are indicated by the red circles, the blue triangles identify the accelerograph stations. The epicentre of the mainshock is indicated by the yellow star. 
occurred and have caused extensive destruction and heavy human loss. The 2017 Sarpol-e-Zahab, Mw $=7.3$ earthquake is one of the most important events of Zagros in recent years. According to the report of the International Institute of Earthquake Engineering and Seismology (IIEES), the fault which caused this earthquake was one related to the plates with northnorthwest direction close to the mountain which has a slope with a very low angle (10-15 degrees) to the eastward.

The study of the attenuation parameters, that is, the Quality factor and the Kappa factor can help to explain the study area in more details. Kappa is a factor which can help comment on the PGA by comparing its value for different conditions and regions. Kappa is also important for simulating the strong ground motion in the region in which there are insufficient records of strong motion, so that empirical equations can be used to predict the strong ground motion (Douglas et al., 2009). In this study, we investigate the Kappa and the Quality factors around the epicentral region of the Sarpol-e-Zahab destructive earthquake.

\section{Data}

In this study 87 aftershock records of Sarpol-e-Zahab earthquake, recorded by the accelerographic stations of the Road, Housing \& Urban Development Research Center of Iran, are used. The distribution of stations that have been used is given in Fig. 1. These aftershocks have local magnitudes $3.8<\mathrm{ML}<5.3$. Their locations were extracted from the ISC (International Seismological Centre) catalogue.

In the study we analysed the S-wave acceleration spectra. There are several methods to isolate S-waves, which select the beginning and ending of the S-wave. One of these methods is the Husid method (Husid, 1967). The method consists of calculating the cumulative energy and then identifing the beginning point $\left(t_{1}\right)$ of the S-wave window as the time to reach the $5 \%$ of total energy, while the final time $\left(t_{2}\right)$ corresponds to the time to reach the $95 \%$ of the total energy. Kinoshita (1994) used the push function of acceleration to detect the end of the S-wave. The envelope function $e(n)$ and the cumulative function $c(k)$ of the acceleration records are defined as follows, respectively: 
$e(n)=\left(a^{2}(n)+H^{2}\{a(n)\}\right)^{1 / 2}$,

$c(k)=\left(k^{-1} \sum_{n=1}^{k} e^{2}(n)\right)^{1 / 2}$.

In Eq. (1), " $a$ " is the acceleration record and " $H$ " is the Hilbert transform of acceleration record. In this method, the ending time of the S-wave is equal to the time when the cumulative envelope function begins to decline.

The sudden cut of the wave has a big effect on the Fourier spectrum of records. Therefore, after selecting the beginning and the end of the time of the S-wave, a suitable taper must be applied. The processes mentioned above for the two horizontal components must be performed and then their geometric mean is to be calculated. We applied the Konno and Ohmachi's (1998) function to taper the spectra. The window function is:

$W\left(f, f_{c}\right)=\left[\frac{\sin \left(\log \left(\frac{f}{f_{c}}\right)^{b}\right)}{\log \left(\frac{f}{f_{c}}\right)^{b}}\right]^{4}$,

where $f_{c}$ represents the central frequency around which the smoothing is performed and assumed $b=20$. This window has a constant width on the logarithmic frequency axis. The domain of frequency in this study is 0.5 to $25 \mathrm{~Hz}$ which amounts to acceleration spectrum in 40 points with equal logarithmic intervals upon having been interpolated. For example, one of the smoothed Fourier transform with Konno and Ohmachi's window is shown in Fig. 2.

\section{3. $K_{0}$ coefficient}

In high frequencies (usually higher than $5 \mathrm{~Hz}$ ), the S-wave acceleration spectrum decreases as an exponential function $\mathrm{e}^{-K \pi f}$ (Anderson and Hough, 1984). Therefore, moving to the log space, the $K$ coefficient will be calculated by fitting with a linear function in high frequency, and finding the slope of its line. In Fig. 3, as an example, the coefficients for two cases of the records, to which the above processes have been applied, are shown. 


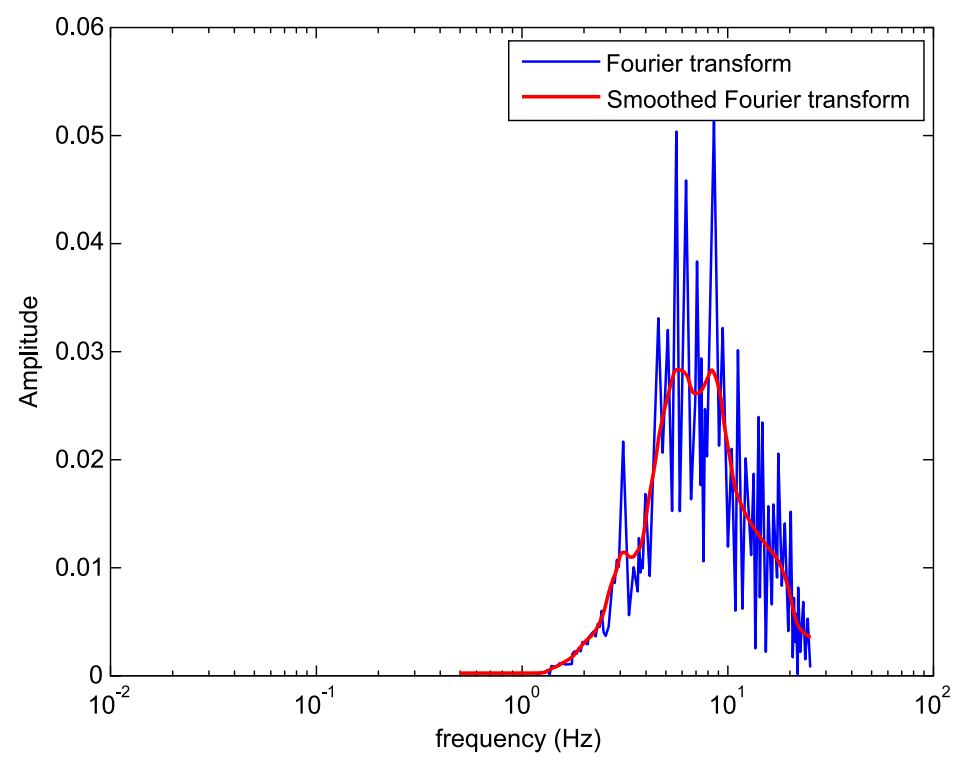

Fig. 2. An example of smoothing the Fourier transform.

To find Kappa coefficient at zero distance $\left(K_{0}\right)$, the distribution diagram of Kappa coefficient is drawn in term of epicentral distance. The $y$-intercept of the line which has the best fitness with this distribution $(K=$ $0.0005( \pm 0.0002) R \mathrm{sec} / \mathrm{km}+0.034( \pm 0.007) \mathrm{sec})$ indicates the amount of $K_{0}$ of the region. According to Fig. $4, K_{0}=0.034 \mathrm{sec}$.

\section{Quality factor $Q$}

In this paper, the Quality factor of the shear waves makes use of spectral decay method (i.e. Anderson and Quass, 1988; Castro et al., 1999). The amplitude spectrum ' $U$ ' is obtained by multiplication of the decay expressions 'A' (i.e. geometric spreading and Quality factor) and the source spectrum 'S':

$\mathrm{U}(f, r)=\mathrm{A}(f, r) \cdot \mathrm{S}(f)$.

By applying natural logarithm, the following equation will result:

$\operatorname{Ln}(\mathrm{U}(f, r) \cdot r)=-(\pi f / \beta \mathrm{Q}(f)) \cdot r+\operatorname{Ln}(\mathrm{S}(f))$, 

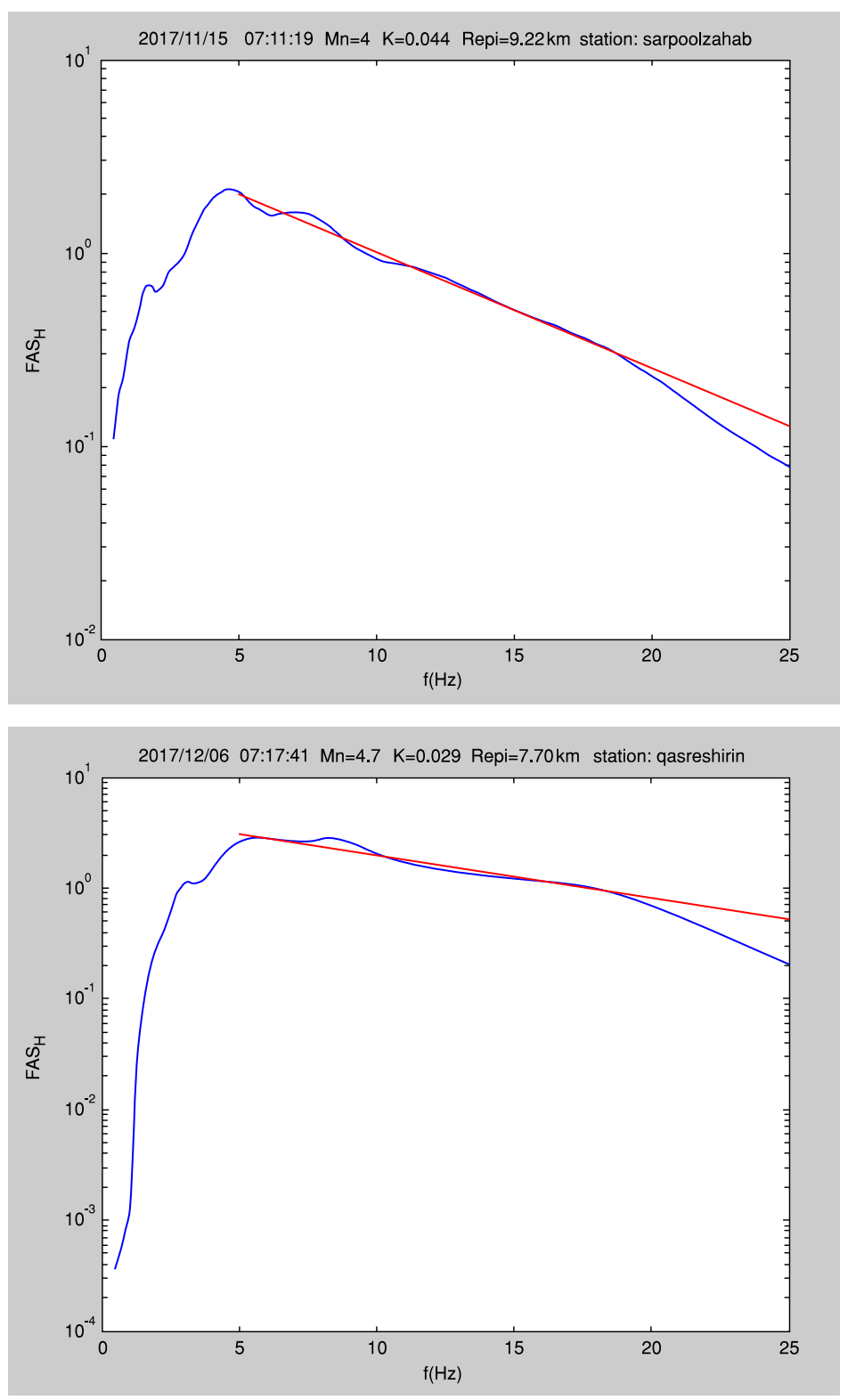

Fig. 3. The Kappa coefficient calculation. The blue curve is the Fourier Amplitude Spectrum (FAS) of the horizontal component and the red line is the best fitting line using the least squares method in high frequencies. 


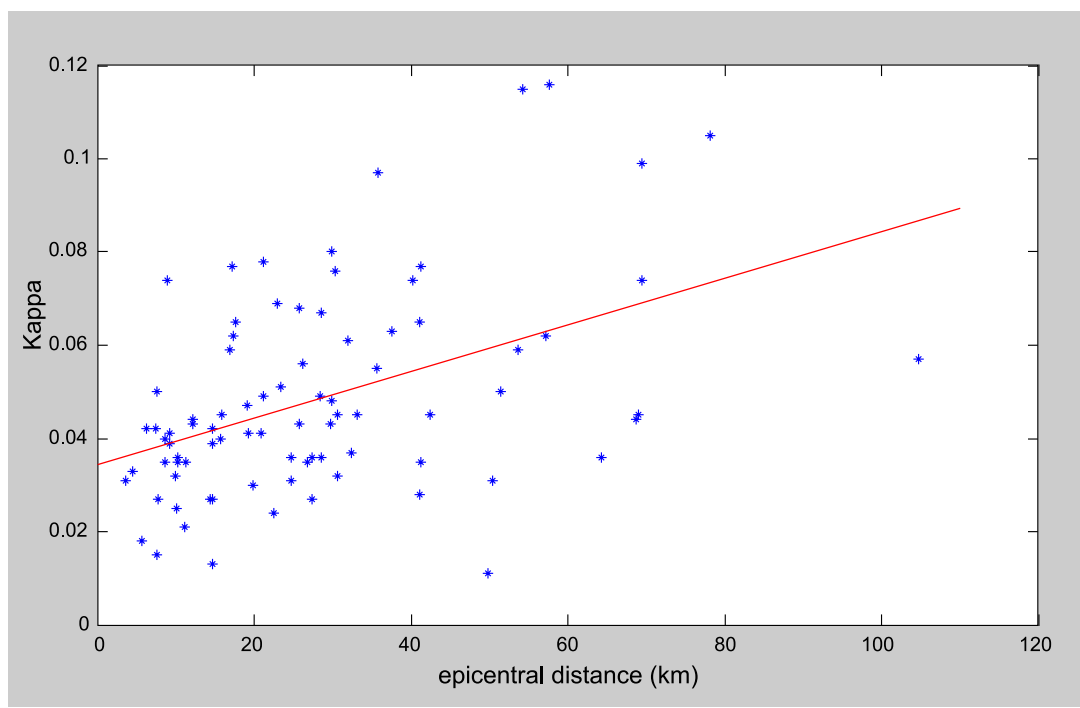

Fig. 4. The diagram of the Kappa coefficient in terms of epicentral distance.

where $\beta$ and $r$ are the S-wave velocity and the hypocentral distance, respectively. Using a linear fitting of the slope " $m$ " for each frequency (Fig. 5), yields the $Q$ filter value as follows:

$Q=-(\pi f / \beta m)$

In this study, aftershock records, magnitudes of which range between 4.5 and 5, have been used to obtain the Quality factor. By applying a bandpass filter to all the records in 6 frequency bands with central frequencies 1.5, 3, 6, 9, 12 and $18 \mathrm{~Hz}$ and a band width of two-thirds of the central frequency, the amount of $Q$ will be obtained (Ma'hood et al., 2009). The obtained Quality factors for each frequency are given in Table 1. Quality coefficients of the shear waves in 6 different frequency bands are given in Fig. 5. Diagram of the frequency relationship of Quality factor is given in Fig. 6.

Table 1. The inferred Quality factor at specified frequencies.

\begin{tabular}{|c|c|c|c|c|c|c|}
\hline$f(\mathrm{~Hz})$ & 1.5 & 3 & 6 & 9 & 12 & 18 \\
\hline$Q$ & $125.93 \pm 22$ & $209.89 \pm 49$ & $359.81 \pm 17.91$ & $503.74 \pm 83.95$ & $651.9 \pm 36.21$ & $913.38 \pm 70.88$ \\
\hline
\end{tabular}




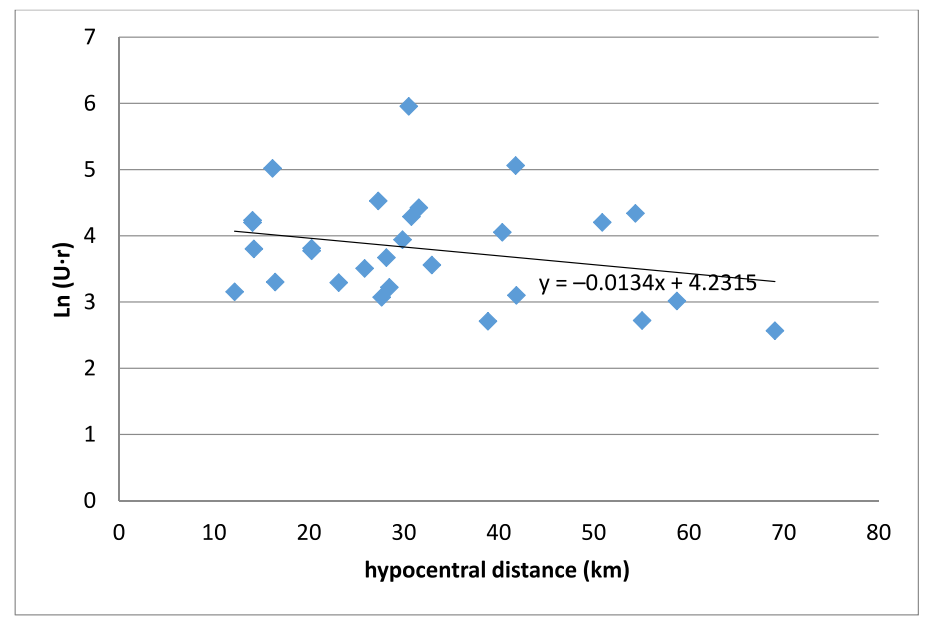

Fig. 5. Determining the Quality factor of the shear waves in 6 different frequency bands.

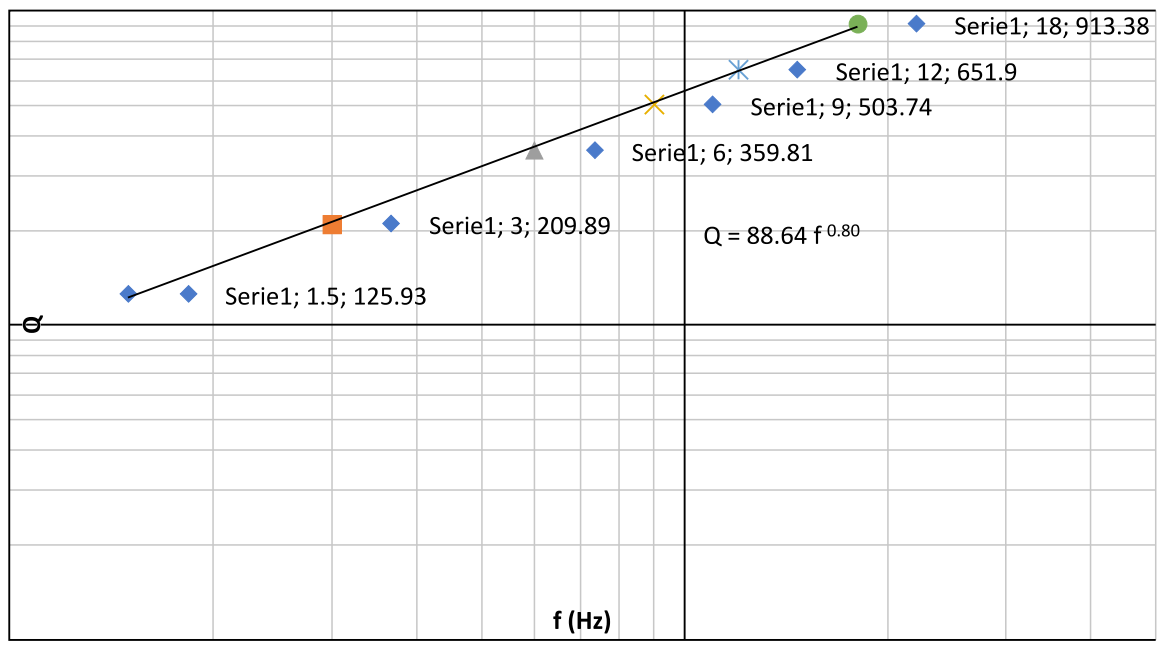

Fig. 6. The diagram of the frequency relationship for the Quality factor.

\section{Discussion and conclusions}

The Kappa parameter is one of the parameters that determine the spectral decay in the high frequency range above the earthquake corner frequency. In this study, $K$ was estimated by using the records of aftershocks of the 
2017 earthquake of Sarpol-e-Zahab. The final value of $K_{0}$, that is, $K$ at zero distance, for the study region is $0.034 \mathrm{sec}$. The Kappa parameter also exhibits an increase with increasing epicentral distance.

The tectonic regions are associated with low values of $Q$ at $1 \mathrm{~Hz}\left(Q_{0}\right)$ and with strong frequency dependence of the Quality factor while, in contrast, stable areas have high values of $Q$ and a weak dependence on frequency (Campillo, 1990). For example Kim et al. (2004) calculated $Q=333 f^{0.54}$ for Central South Korea as seismically stable regions. The obtained Quality factor for the study area is $Q(f)=88.6 f^{0.8}$. Thus, this low value of $Q_{0}$ and strong frequency dependence correspond to those of the seismically active regions. Due to the high activity of the Zagros suture zone, this result was not unexpected for the $Q$ factor.

In order to compare the $Q$ parameter obtained in this study with other similar studies in the Zagros region, two previous works by Hamzehloo et al. (2010) and Sadeghi-Bagherabadi et al. (2020) have been considered. They estimated the $Q$ factor to be $121 f^{0.55}$ and $141 f^{0.84}$, respectively. Hamzehloo et al. (2010) analysed the strong motion accelerograms of the moderate

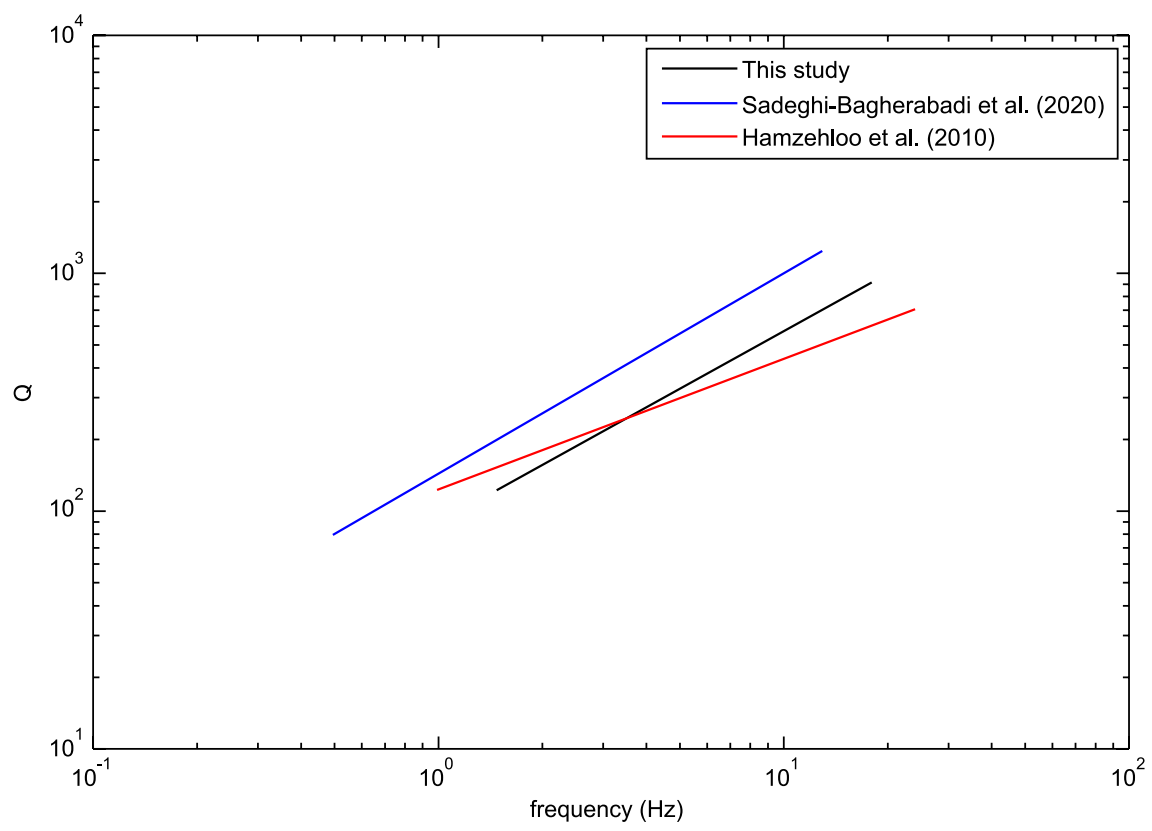

Fig. 7. Diagram of the Quality factor for 3 different studies. 
March 31, 2006, Mw = 6.1, Darb-e-Astane earthquake (Fig. 1) of western Iran. The frequency dependence diagram of $Q$ for these two works, along with the diagram obtained in this study, is shown in Fig. 7. In a general review, the correspondence between the graphs is obvious and it seems that the small differences between them are due to the differences in the data, the frequency range and the applied method. However, the common point of these studies and the present study is the confirmation of the high activity of Zagros.

Acknowledgements. As mentioned in the text of this paper, in this study we used accelerometer network data of Road, Housing \& Urban Development Research Center of Iran. We thank them for providing these data. Figures were produced using the Generic Mapping Tools v. 4.2.1 (http://www.soest.hawaii.edu/gmt/, Wessel and Smith, 1998) and MATLAB software.

\section{References}

Anderson J. G., Hough S. E., 1984: A model for the shape of the Fourier amplitude spectrum of acceleration at high frequencies. Bull. Seismol. Soc. Am., 74, 5, 19691993.

Anderson J. G., Quass R., 1988: The Mexico Earthquake of September 19, 1985-Effect of Magnitude on the Character of Strong Ground Motion: An Example from the Guerrero, Mexico Strong Motion Network. Earthq. Spectra, 4, 3, 635-646, doi: 10.1193/1.1585494.

Castro R. R., Monachesi G., Mucciarelli M., Trojani L., Pacor F., 1999: P- and S-wave attenuation in the region of Marche, Italy. Tectonophysics, 302, 1-2, 123-132, doi: 10.1016/S0040-1951(98)00277-7.

Campillo M., 1990: Propagation and attenuation characteristic of the crustal phase Lg. Pure Appl. Geophys., 132, 1-19, doi: 10.1007/BF00874355.

Douglas J., Gehl P., Bonilla L. F., Scotti O., Régnier J., Duval A.-M., Bertrand E., 2009: Making the most of available site information for empirical ground-motion prediction. Bull. Seismol. Soc. Am., 99, 3, 1502-1520, doi : 10.1785/0120080075.

Hamzehloo H., Rahimi H., Sarkar I., Mahood M., Mirzaei Alavijeh H., Farzanegan E., 2010: Modeling the strong ground motion and rupture characteristics of the March 31, 2006, Darb-e-Astane earthquake, Iran, using a hybrid of near-field SH-wave and empirical Green's function method. J. Seismol., 14, 169-195, doi: 10.1007/s10950009-9159-x.

Husid R., 1967: Gravity effects on the earthquake response of yielding structures. Dissertation (Ph.D.), Report of Earthquake Engineering Research Laboratory, California Institute of Technology, Pasadena, California, https://resolver.caltech.edu/Cal techETD : etd-09202002-143339, doi : 10.7907/9XAB-6V59. 
Kim K. D., Chung T. W., Kyung J. B., 2004: Attenuation of high-frequency P and S waves in the crust of Choongchung provinces, central South Korea, Bull. Seismol. Soc. Am., 94, 3, 1070-1078, doi: 10.1785/0120030137.

Kinoshita S., 1994: Frequency-dependent attenuation of shear waves in the crust of the southern Kanto area, Japan. Bull. Seismol. Soc. Am., 84, 5, 1387-1396.

Konno K., Ohmachi T., 1998: Ground-motion characteristics estimated from spectral ratio between horizontal and vertical components of microtremor. Bull. Seismol. Soc. Am., 88, 1, 228-241.

Ma'hood M., Hamzehloo H., Doloei G. J., 2009: Attenuation of high frequency P and S waves in the crust of the East-Central Iran. Geophys. J. Int., 179, 3, 1669-1678, doi : 10.1111/j.1365-246X.2009.04363.x.

Mirzaei N., Gao M., Chen Y. T., 1998: Seismic source regionalization for seismic zoning of Iran: Major seismotectonic provinces. J. Earthq. Pred. Res., 7, 4, 465-495.

Sadeghi-Bagherabadi A., Sobouti F., Pachhai S., Aoudia A., 2020: Estimation of geometrical spreading, quality factor and kappa in the zagros region. Soil Dyn. Earthq. Eng., 133, 106110, doi: 10.1016/j.soildyn.2020.106110.

Wessel P., Smith W. H. F., 1998: New, improved version of generic mapping tools released. Eos Trans. AGU, 79, 47, 579-579, doi: 10.1029/98E000426. 